\section{Fatores associados ao risco de internação por acidentes de trânsito no Município de Maringá-PR}

\section{Factors associated to risks of hospital admissions due to traffic accidents in the city of Maringa, $P R$}

\section{Dorotéia Fátima Pelissari de Paula Soares' Marilisa Berti de Azevedo Barros ${ }^{2}$}

'Departamento de Enfermagem. Centro de Ciências da Saúde. Universidade Estadual de Maringá, Paraná

2Departamento de Medicina Preventiva e Social. Faculdade de Ciências Médicas. Universidade Estadual de Campinas, São Paulo

\section{Resumo}

Objetivo: Analisar os fatores associados ao risco de internação da coorte constituída pelas vítimas dos acidentes de trânsito ocorridos no Município de Maringá - PR, no ano 2000. Método: A coorte foi composta pelas vítimas que tiveram registro no Serviço Integrado de Atendimento ao Trauma em Emergência (SIATE) ou em Boletim de Ocorrência Policial (BO). Foi feita vinculação dos bancos gerados com os dados do SIATE, do BO, da Autorização de Internação Hospitalar (AIH-SUS) e da Comunicação de Internação Hospitalar $(\mathrm{CIH})$. Foram realizadas análises univariadas e de regressão múltipla de Cox para identificar, entre as variáveis relacionadas à vítima, ao acidente e ao condutor do veículo, os fatores de risco para internação. Resultados: Foram identificadas 3.468 pessoas vitimadas em 2.725 acidentes. O risco médio de internação foi de 19,4/100 vítimas (673 internações). A análise de regressão múltipla identificou como categorias de maior risco de internação: vítimas pedestres, ciclistas e motociclistas; com idade acima de 50 anos; vitimadas em colisão com transporte pesado ou ônibus; em acidentes ocorridos de madrugada e de tarde, em algumas regiões da cidade; e sendo o condutor do veículo residente no próprio município. Conclusão: Conclui-se que os programas de redução dos acidentes de trânsito devem considerar os subgrupos mais vulneráveis a acidentes graves e que as múltiplas determinações do risco apontam para a necessidade de ações articuladas dos diversos setores de governo e segmentos da sociedade nesses programas.

Palavras-chave: Acidentes de trânsito. Fatores de risco. Internação.

Correspondência: Dorotéia Fátima Pelissari de Paula Soares. Rua Monte Carlo, 385, Jardim Novo Horizonte. CEP 87010-060, Maringá, Paraná. E-mail: doroteiasoares@uol.com.br 
Abstract

Objective: To analyze the factors associated to risks in hospital admissions of the population of traffic accident victims in the city of Maringa, PR, in 2000. Method: The cohort comprised the victims registered by the Integrated Trauma Care Emergency Services (SIATE) or in Police Records (BO). We linked the databases generated by SIATE, BO, Hospital Admission Authorizations (AIH-SUS), and Hospital Admission Communications $(\mathrm{CIH})$. Several univariate analyses and Cox's multiple regression analyses were performed to identify risk factors for hospital admissions among the variables related to victims, accidents and vehicle drivers. Results: 3,468 victims in 2,725 accidents were identified. The average hospital admission risk was 19.4/100 victims (673 hospital admissions). The major categories for hospital admissions identified by the multiple regression analysis were: pedestrians, bikers, and motorcyclists; victims over 50 years of age; individuals involved in accidents with heavy load trucks or buses; accidents taking place at dawn and in the afternoon, in some areas of the city; and the vehicle driver living in the city of Maringá. Conclusion: We concluded that traffic accident reduction programs should take into consideration the most vulnerable subgroups that are subject to serious accidents. We also concluded that multiple risk determination points toward the need for joint actions by the various government sectors and segments of society in these programs.

Keywords: Traffic accidents. Risk factor. Hospital admission.

\section{Introdução}

A violência é reconhecida como um dos problemas de maior magnitude e transcendência no Brasil pelo forte impacto na morbidade, mortalidade e qualidade de vida da população. Os acidentes de trânsito (AT) representam mais de um quarto das mortes violentas do país e respondem por $20 \%$ das internações por lesões e envenenamentos, ocupando o segundo lugar no conjunto das causas externas ${ }^{1}$. Foi verificado que as internações decorrentes de AT financiadas pelo Sistema Único de Saúde (SUS) apresentam custo-dia e gasto-médio superiores aos das internações por causas naturais ${ }^{1}$.

As taxas de acidentes de transporte observadas no Brasil, que incluem os acidentes de trânsito, encontram-se entre as mais elevadas do mundo (18,9/100.000 habitantes), tendo sido responsáveis por 33.620 mortes e 114.189 mil internações em $2003^{2}$.

As conseqüências dos AT, medidas em mortes, em demanda à atenção pré-hospitalar, hospitalar e de reabilitação, assim como as incapacidades geradas, os anos potenciais de vida perdidos, e o impacto nas famílias das vítimas e na sociedade em geral, têm levado instituições internacionais e nacionais a reconhecer a sobrecarga que estes acidentes produzem nos sistemas de saúde e o significativo custo social e econômico que representam ${ }^{3,4}$.

As concepções relativas aos acidentes de trânsito modificaram-se a partir da década de 1960, quando passaram a ser considerados como eventos preveníveis e causados pela interação de múltiplos fatores, em especial os humanos, os relacionados aos veículos a motor e às condições das vias públicas. Os estudos passaram a identificar medidas efetivas de controle e redução da ocorrência e da gravidade dos acidentes, tais como: modificações no desenho de vias e estradas, ampliação dos itens de segurança dos veículos, e medidas legislativas que reorientam o comportamento de condutores e passageiros de veículos ${ }^{5}$. 
Em âmbito mundial, a questão da segurança no trânsito passou a ser examinada com interesse maior a partir da década de 1950, enquanto no Brasil a importância dada a essa questão ainda é recente e está sendo implementada por meio de campanhas nos níveis federal, estadual e municipal $^{6}$.

O Ministério da Saúde visando instrumentalizar políticas direcionadas aos acidentes e violências lançou, em 2000, o Programa de Redução da Morbimortalidade por Acidentes e Violências, com destaque para as ações de prevenção e de promoção da saúde, por meio da articulação e mobilização de setores governamentais, não-governamentais e da população em geral $^{4}$.

Têm sido apontados no Brasil contextos que contribuem para as elevadas taxas de acidentes de trânsito como a falta de planejamento urbano, o desenho inapropriado das vias de tráfego, o comportamento imprudente dos motoristas, o grande movimento de pedestres sob condições inseguras e a precariedade da educação e da fiscalização do trânsito ${ }^{7}$.

No município de Maringá, semelhante ao que ocorre em outros centros urbanos do país, as mortes violentas ocupam lugar de proeminência entre as causas de óbito. Em 2000, as causas externas ocuparam o $3^{\circ}$ lugar entre os principais grupos de causas de mortalidade, com 9,7\% dos óbitos; entre as causas externas destacaram-se os acidentes de trânsito (45,6\%), seguidos em freqüência por homicídios (16,8\%), quedas acidentais $(12,8 \%)$, suicídios $(7,2 \%)$ e afogamentos $(4,0 \%)$.

O impacto social e na saúde provocado pelos acidentes de trânsito tem sido extensamente registrado, assim como a natureza evitável do evento e de suas conseqüências. Experiências nacionais e internacionais têm registrado sucesso na redução da ocorrência e gravidade dos acidentes com diferentes modalidades de intervenção. O risco de internação de vítimas de acidentes constitui um indicador da gravidade dos acidentes, podendo ser uti- lizado para monitorar tendências, além de quantificar um evento que representa um custo importante na demanda aos serviços de saúde. Dada a carência de estudos de acidentes de trânsito com desenho tipo coorte, que permitam estimar os riscos de internação, pretende-se com o presente estudo contribuir com subsídios para o entendimento de fatores de risco de internação das vítimas de acidentes de trânsito, analisando os acidentes ocorridos em Maringá-PR, no ano 2000.

\section{Material e métodos}

\section{Local do estudo}

Maringá é um município de porte médio, situado ao Sul do Brasil, na região Noroeste do Estado do Paraná, que contava em 2000 com uma população de 288.653 habitantes ${ }^{8}$, marcadamente urbana (98\%). Maringá polariza uma vasta área por seu estratégico posicionamento territorial, tornando-se ponto de convergência de importantes rodovias federais e estaduais. A localização e o crescimento fizeram com que Maringá passasse a apresentar problemas típicos de metropolização, como o crescimento disperso em áreas limítrofes e a formação de "cidades dormitórios" nos municípios onde a resposta econômica e a geração de empregos é mais lenta ${ }^{9}$.

O traçado viário da cidade foi planejado, com ruas e avenidas largas, calçadas amplas e muitas praças rotatórias, de onde chegam e partem vias que caracterizam os subsistemas radiais da cidade. $\mathrm{O}$ eixo, formado pela Avenida Colombo e a linha férrea, cruza a cidade no sentido LesteOeste, separando a malha urbana em duas partes, configurando-se em divisas de transposição conflituosa, assim como, alguns pontos críticos relacionados com a fluidez de circulação na região central, proporcionando maior risco de ocorrência de acidentes de trânsito ${ }^{9}$.

A sinalização vertical existente é constituída por placas de regulamentação e advertência, observando-se de modo ge- 
ral problemas de visibilidade, que fica prejudicada pela intensa arborização e falta de padronização na colocação e nas dimensões das placas.

A rede hospitalar de Maringá é composta por 5 hospitais gerais privados, um hospital psiquiátrico privado, um hospital filantrópico geral e dois hospitais públicos. As internações por acidentes de trânsito que ocorrem em Maringá são realizadas nos hospitais de Maringá e no Hospital Metropolitano de Sarandi (município limítrofe com Maringá).

Maringá conta com um serviço de atendimento pré-hospitalar (Sistema Integrado de Atendimento ao Trauma em Emergência-SIATE), implantado em 1997, que tem por objetivo prestar assistência médica de emergência a vítimas de traumas, garantindo suporte básico de vida no local da ocorrência e transporte para hospital de referência.

\section{Desenho e população de estudo}

Foi realizado um estudo de coorte nãoconcorrente, com 3.468 vítimas de acidentes de trânsito que tiveram lugar dentro do limite geográfico do município de Maringá, no período de $1^{\circ}$ de janeiro a 31 de dezembro de 2000, cujo sinistro foi registrado nos Boletins de Ocorrência Policial (BO) e as vítimas atendidas pelo SIATE. Foi considerado acidente de trânsito todo acidente ocorrido com veículo em via pública ${ }^{10}$.

\section{Variáveis de estudo}

Variável dependente: ocorrência de internação.

Variáveis independentes:

- perfil epidemiológico das vítimas: sexo, faixa etária, município de residência, categoria da vítima, número de lesões, se houve atendimento no local do acidente e gravidade das lesões avaliada pela Escala de Coma de Glasgow (ECG) (11) e pela Escala de Trauma Revisada (ETR) (12), uso de equipamento de proteção e estado de alcoolização.
- características dos acidentes : dia, mês, horário, tipo, colisão com transporte pesado, área do acidente, condições do local, número de condições desfavoráveis, registro no BO e registro no SIATE.

- perfil epidemiológico dos condutores: idade, sexo, local de residência, categoria, escolaridade, estado de alcoolização, equipamento de proteção, tempo de habilitação, tempo de uso do veículo e número de condutores envolvidos no acidente.

Para conhecer a categoria das vítimas, todos os acidentes foram codificados com base no Capítulo XX da CID- $10^{10}$.

\section{Fontes de dados}

Para o estudo foram utilizados dados procedentes de quatro fontes de informação: Registro de Atendimento do Socorrista (RAS) do SIATE, Boletim de Ocorrência (BO), Autorização de Internação Hospitalar (AIH-SUS) e Comunicação de Internação Hospitalar (CIH).

\section{Coleta e processamento dos dados}

Do SIATE foram obtidos dados de um banco informatizado, complementados, para este estudo, com outras informações existentes no Relatório de Atendimento do Socorrista (RAS). Os dados dos BOs foram coletados no $4^{\circ}$ Batalhão da Polícia Militar e digitados em formulário informatizado desenvolvido para este estudo.

Os bancos dos dados de internação (AIH e CIH) foram obtidos da Secretaria de Saúde do Município (Hospitais de Maringá) e da 15ª Regional de Saúde (Hospital Metropolitano de Sarandi) em formato DBF. Os dados obtidos foram referentes ao período de janeiro a dezembro de 2000 e janeiro a junho de 2001, considerando que, para fins de cobrança, as AIHs são apresentadas ao gestor local no mês seguinte à sua autorização, havendo casos de apresentação, em menor número, nos meses subseqüentes. O serviço de atendimento pré-hospitalar (SIATE) está organi- 
zado de forma regionalizada, onde as vítimas são encaminhadas aos hospitais (públicos e privados) que são referência de acordo com a região de ocorrência do acidente.

Para a coleta de dados e vinculação dos bancos foi utilizado o programa Excel da Microsoft, que possibilitou importar dados de outros bancos, extrair listagens e fazer cruzamento das variáveis.

A coleta e digitação das informações, a análise de consistência e as correções foram realizadas pelo autor principal.

O projeto de pesquisa do presente estudo foi aprovado pelo Comitê Permanente de Ética em Pesquisa Envolvendo Seres Humanos da Universidade Estadual de Maringá.

\section{Vinculação dos bancos de dados}

Inicialmente, foi realizado o "linkage" dos bancos de dados BO e SIATE, por meio de um programa que fazia busca da vítima no banco do SIATE e transferia os dados para um banco único, que passou a ser chamado banco BO/SIATE. Este banco constituía-se de 3.468 vítimas, das quais 2.470 haviam sido registradas na fonte $\mathrm{BO}$, 3.151 na fonte SIATE, e 2.153 possuíam registro em ambas as fontes.

Um banco organizado com dados de $\mathrm{AIH} / \mathrm{CIH}$ foi então vinculado ao banco BO/ SIATE por meio de um programa que usava como variáveis chaves o nome e a idade da vítima e a data do acidente. Encontrado o paciente, as informações de interesse sobre a internação foram transferidas para o banco BO/SIATE, que nessa fase passou a ser chamado banco BO/SIATE/ $\mathrm{AIH} / \mathrm{CIH}$.

\section{Análise dos dados}

Foram estimadas as incidências de internação (risco de internação) segundo as categorias de cada variável independente e as razões entre as incidências (riscos relativos) e respectivos intervalos de 95\% de confiança. As variáveis cuja associação com a internação (teste $\div^{2}$ ) apresentou $\mathrm{p}<0,20$ foram incluídas na análise de regressão múltipla de Cox, com critério de seleção Stepwise ${ }^{13}$. As variáveis indicadoras da gravidade da lesão não foram incluídas no modelo por já constituírem um resultado dos fatores de interesse do estudo (características demográficas das vítimas, características dos acidentes e dos condutores) e serem determinantes diretas da conduta de internação. O nível de significância adotado para permanecer no modelo foi de $5 \%$.

Foram calculados riscos relativos (RR) e intervalos de confiança de 95\% (IC 95\%). O programa computacional utilizado para a análise estatística foi o SAS System for Windows (Statistical Analysis System), versão 6.12 .

\section{Resultados}

A coorte estudada ( $n=3468)$ apresentou um risco médio de internação de 19,4/ 100 vítimas (673 internações).

A análise da internação segundo as características das pessoas acidentadas (Tabela 1) mostrou maior risco de hospitalização para vítimas do sexo feminino (RR $=1,17$ ), com idade igual ou superior a 50 anos $(R R=1,63)$, residentes em Maringá $(\mathrm{RR}=1,26)$ e vítimas das categorias pedestre $(R R=1,77)$ e motociclista $(R R=1,24)$. A análise das variáveis indicadoras da gravidade das lesões apontou risco relativo de 1,77 para vítimas com ECGI moderado ou grave, de 2,10 para vítimas com ETR moderado ou grave e 1,37 para as que receberam atendimento médico no local do acidente. Foram observados riscos crescentes de internação com o aumento do número de lesões, chegando a um risco relativo de 1,76, para vítimas com 4 ou mais lesões.

A análise das hospitalizações segundo variáveis relacionadas às características dos acidentes (Tabela 2) revelou riscos maiores para as vítimas pedestres quando atropeladas por moto $(\mathrm{RR}=3,59)$ e por carro/caminhonete $(\mathrm{RR}=3,24)$; vítimas ciclis- 
Tabela 1 - Distribuição das vítimas internadas, risco relativo e respectivo intervalo de confiança de 95\%, segundo características das vítimas e indicadores de gravidade das lesões. Maringá-PR, 2000

Table 1 - Distribution of interned victims, their relative risk and their 95\% interval of trust, according to the victims' characteristics and indicators of lesions severity. Maringá-PR, 2000

\begin{tabular}{|c|c|c|c|c|c|c|}
\hline Variável & $\begin{array}{l}\text { Número } \\
\text { de vítimas }\end{array}$ & $\begin{array}{l}\text { №.e \% de } \\
\text { internação }\end{array}$ & $\begin{array}{c}\text { Risco de } \\
\text { internação (\%) }\end{array}$ & $\mathrm{RR}$ & IC (95\%) & $P$ \\
\hline Sexo & & & & & & 0,049 \\
\hline Masculino & 2632 & $491 \quad(73,0)$ & 18,7 & 1 & - & \\
\hline Feminino & 834 & $182(27,0)$ & 21,8 & 1,17 & $1,01-1,36$ & \\
\hline Faixa etária & & & & & & $<0,001$ \\
\hline$<20$ & 908 & $156(23,2)$ & 17,2 & 1 & - & \\
\hline $20-29$ & 1158 & $222(33,0)$ & 24,4 & 1,12 & $0,93-1,34$ & \\
\hline $30-49$ & 1027 & $195(29,0)$ & 19,0 & 1,11 & $0,91-1,34$ & \\
\hline 50 e mais & 357 & $100(14,9)$ & 28,0 & 1,63 & $1,31-2,03$ & \\
\hline Residência & & & & & & 0,023 \\
\hline Residente & 2830 & $575(86,2)$ & 20,3 & 1,26 & $1,03-1,54$ & \\
\hline Não residente & 572 & $92(13,8)$ & 16,1 & 1 & - & \\
\hline Categoria & & & & & & $<0,001$ \\
\hline Pedestre & 330 & $98(14,6)$ & 29,7 & 1,77 & $1,41-2,22$ & \\
\hline Ciclista & 913 & $142(21,1)$ & 15,6 & 0,93 & $0,75-1,15$ & \\
\hline Motociclista & 1338 & $278(41,3)$ & 20,8 & 1,24 & $1,03-1,49$ & \\
\hline Ocupante de carro & 780 & $131(19,5)$ & 16,8 & 1 & - & \\
\hline Ocupante de demais veículos e outros & 107 & $24(3,6)$ & 22,4 & 1,34 & $0,91-1,96$ & \\
\hline Escala de Coma de Glasgow (ECGI) & & & & & & $<0,001$ \\
\hline Grave e moderado & 105 & $38(6,0)$ & 36,2 & 1,77 & $1,36-2,30$ & \\
\hline Leve & 2887 & $591(94,0)$ & 20,5 & 1 & - & \\
\hline Escala de Trauma Revisado (ETR) & & & & & & $<0,001$ \\
\hline Grave e moderado & 39 & $18(3,1)$ & 46,2 & 2,10 & $1,49-2,97$ & \\
\hline Leve & 2579 & $566(96,9)$ & 21,9 & 1 & - & \\
\hline Atendimento Médico no Local & & & & & & $<0,001$ \\
\hline Sim & 1184 & $287(48,6)$ & 24,2 & 1,37 & $1,19-1,58$ & \\
\hline Não & 1718 & $304(51,4)$ & 17,7 & 1 & - & \\
\hline № de lesões/vítima & & & & & & $<0,001$ \\
\hline Menor ou igual 2 & 1570 & $279(61,2)$ & 17,8 & 1 & - & \\
\hline 3 & 720 & $177(38,8)$ & 24,6 & 1,38 & $1,17-1,63$ & \\
\hline 4 ou mais & 523 & $164(36,0)$ & 31,4 & 1,76 & $1,50-2,08$ & \\
\hline
\end{tabular}

tas com colisão com veículo de transporte pesado ( $R R=4,60)$, com carro / caminhonete ( $R R=2,48)$ e com moto $(R R=1,99)$; vítimas motociclistas em colisão com objeto fixo ( $R R=4,18)$, com veículo de transporte pesado $(\mathrm{RR}=2,68)$ e com carro/caminhonete $(R R=2,21)$. Para os acidentes que envolveram veículos de transporte pesado, o risco de internação foi $42 \%$ maior. Também apresentaram maior risco de hospitalização as vítimas dos acidentes ocorridos nas regiões Noroeste $(R R=2,20)$, Sudoeste $(R R=2,08)$ e Centro $(R R=2,13)$. Menor risco foi observado para os aciden- tes ocorridos no primeiro trimestre do ano e, segundo o horário, foram de maior risco os ocorridos de madrugada e à noite. Acidentes ocorridos à noite em local com iluminação boa apresentaram risco de internação $32 \%$ maior que os ocorridos durante o dia. Os acidentes com registro na fonte $\mathrm{BO}$ apresentaram um risco relativo de 3,17 e os com registro no SIATE de 1,59.

A análise do risco de internação das vítimas segundo as características dos condutores de veículos envolvidos nos acidentes (Tabela 3) mostrou risco maior de internação quando o condutor era residen- 
Tabela 2 - Distribuição das vítimas internadas, risco relativo e respectivo intervalo de confiança de 95\%, segundo características dos acidentes. Maringá-PR, 2000.

Table 2 - Distribution of interned victims, their relative risk and their 95\% interval of confidence, according to the accidents characteristics. Maringá-PR, 2000.

\begin{tabular}{|c|c|c|c|c|c|c|}
\hline Variável & $\begin{array}{l}\text { Número } \\
\text { de vítimas }\end{array}$ & $\begin{array}{l}\text { №.e \% de } \\
\text { internação }\end{array}$ & $\begin{array}{c}\text { Risco de } \\
\text { internação (\%) }\end{array}$ & $\mathrm{RR}$ & IC (95\%) & $P$ \\
\hline \multicolumn{6}{|l|}{ Época do ano } & 0,042 \\
\hline 10 Trimestre & 725 & $117(17,4)$ & 16,1 & 0,77 & $0,63-0,94$ & \\
\hline $2^{\circ}$ Trimestre & 955 & $180(26,7)$ & 18,8 & 0,99 & $0,75-1,07$ & \\
\hline $3^{\circ}$ Trimestre & 821 & $173(25,7)$ & 21,1 & 1,00 & $0,84-1,20$ & \\
\hline $4^{\circ}$ Trimestre & 967 & $203(30,2)$ & 21,0 & 1 & - & \\
\hline \multicolumn{5}{|l|}{ Tipo de acidente com pedestre } & 0,022 & \\
\hline Col. c/ moto (V02) & 100 & $35(35,7)$ & 35,0 & 3,59 & $1,36-9,45$ & \\
\hline Col. c/ carro/caminhonete (V03) & 177 & $56(57,1)$ & 31,6 & 3,24 & $1,25-8,43$ & \\
\hline Col. c/ transp. pesado (V04) & 12 & $3(3,1)$ & 25,0 & 2,56 & $0,66-9,90$ & \\
\hline Col. c/ demais veículos e outros (V01,V09) & 9) 41 & $4(4,1)$ & 9,8 & 1 & - & \\
\hline \multicolumn{6}{|l|}{ Tipo de acidente com ciclista } & $<0,001$ \\
\hline Col.c/ moto (V02) & 75 & $12(8,5)$ & 16,0 & 1,99 & $1,11-3,54$ & \\
\hline Col. c/ carro/caminhonete (V13) & 337 & $72(50,7)$ & 21,4 & 2,48 & $1,73-3,57$ & \\
\hline Col. c/ transp. pesado (V14) & 48 & $19(13,4)$ & 39,6 & 4,60 & $2,90-7,29$ & \\
\hline $\begin{array}{l}\text { Col. c/ demais veículos e outros } \\
(\mathrm{V} 10, \mathrm{~V} 11, \mathrm{~V} 17, \mathrm{~V} 19)\end{array}$ & 453 & $39(27,5)$ & 8,6 & 1 & - & \\
\hline \multicolumn{6}{|l|}{ Tipo de acidente com motociclista } & 0,001 \\
\hline Col. c/ outra moto (V22) & 79 & $8(2,9)$ & 10,1 & 1 & - & \\
\hline Col. c/ carro/caminhonete (V23) & 723 & $162(58,3)$ & 22,4 & 2,21 & $1,13-4,33$ & \\
\hline Col. c/ transp. pesado (V24) & 59 & $16(5,8)$ & 27,1 & 2,68 & $1,23-5,84$ & \\
\hline Col. c/ objeto fixo (V27) & 26 & $11(4,0)$ & 42,3 & 4,18 & $1,89-9,26$ & \\
\hline $\begin{array}{l}\text { Col. c/ demais veículos e outros } \\
\text { (V20,V21,V26,V28,V29) }\end{array}$ & 451 & $81(29,1)$ & 18,0 & 1,77 & $0,89-3,52$ & \\
\hline \multicolumn{6}{|l|}{ Colisão com transporte pesado ou ônibus } & 0,009 \\
\hline Sim & 185 & $50(7,4)$ & 27,0 & 1,42 & $1,11-1,82$ & \\
\hline Não & 3283 & $623(92,6)$ & 19,0 & 1 & - & \\
\hline \multicolumn{6}{|l|}{ Região de ocorrência do acidente } & $<0,001$ \\
\hline Centro & 1062 & $264(40,0)$ & 24,9 & 2,13 & $1,73-2,63$ & \\
\hline Nordeste e Norte & 883 & $103(15,6)$ & 11,7 & 1 & - & \\
\hline Sudeste & 561 & $73(11,1)$ & 13,0 & 1,12 & $0,84-1,48$ & \\
\hline Sudoeste & 479 & $116(17,6)$ & 24,2 & 2,08 & $1,63-2,64$ & \\
\hline Noroeste & 366 & $94(14,2)$ & 25,7 & 2,20 & $1,71-2,83$ & \\
\hline Rural & 56 & $10(1,5)$ & 17,9 & 1,53 & $0,85-2,76$ & \\
\hline \multicolumn{6}{|l|}{ Horário } & 0,088 \\
\hline Madrugada & 289 & $69(10,3)$ & 23,9 & 1,35 & $1,07-1,71$ & \\
\hline Manhã & 657 & $133(19,8)$ & 20,2 & 1,15 & $0,95-1,39$ & \\
\hline Tarde & 1274 & $225(33,4)$ & 17,7 & 1 & - & \\
\hline Noite & 1248 & $246(36,6)$ & 19,7 & 1,12 & $0,95-1,31$ & \\
\hline \multicolumn{6}{|l|}{ Luminosidade } & 0,004 \\
\hline Dia & 1577 & $335(56,0)$ & 21,2 & 1 & - & \\
\hline Noite c/ iluminação boa & 586 & $164(27,4)$ & 28,0 & 1,32 & $1,12-1,55$ & \\
\hline Noite c/ iluminação fraca e s/ iluminação & o 419 & $99(16,6)$ & 23,6 & 1,11 & $0,91-1,35$ & \\
\hline \multicolumn{6}{|c|}{ Registro no BO } & $<0,001$ \\
\hline Sim & 2470 & $597(88,7)$ & 24,2 & 3,17 & $2,53-3,98$ & \\
\hline Não & 998 & $76(11,3)$ & 7,6 & 1 & - & \\
\hline \multicolumn{6}{|l|}{ Registro no SIATE } & 0,002 \\
\hline Sim & 3151 & $633(94,1)$ & 20,1 & 1,59 & $1,18-2,14$ & \\
\hline Não & 317 & $40(5,9)$ & 12,6 & 1 & - & \\
\hline
\end{tabular}


te em Maringá $(R R=1,39)$, condutor de veículo de transporte pesado ou ônibus $(\mathrm{RR}=1,36)$ e havia apenas um condutor envolvido ( $R R=1,24)$.

Entre as variáveis que na análise univariada não mostraram associação com internação ( $\mathrm{p}>=0,05)$, encontram-se: o estado de alcoolização da vítima e se fazia uso de equipamento de proteção. Das variáveis relativas aos acidentes, não apresentaram significância: o dia da semana, o acidente com ocupante de carro, a conservação do local, a superfície do local, a sinalização e a presença de condições desfavoráveis. Quanto aos condutores envolvidos nos acidentes, as variáveis que não apresentaram associação com a internação foram: sexo, faixa etária, escolaridade, estado de alcoolização, uso de equipamento de proteção, tempo de habilitação e data de fabricação do veículo envolvido.

Os resultados da análise de regressão logística múltipla para o risco de internação por acidentes de trânsito estão apresentados na Tabela 4. Permaneceram no modelo apresentando maior risco de hospitalização: as categorias de pedestres $(R R=2,19)$, ciclistas $(R R=1,65)$ e motoci- clistas $(\mathrm{RR}=1,43)$, as vítimas com 50 anos ou mais de idade, os acidentes envolvendo colisão com veículo de transporte pesado ou ônibus, os acidentes ocorridos à noite ou de madrugada, os ocorridos nas regiões Noroeste, Sudoeste e Centro e os condutores serem residentes no município de Maringá.

\section{Discussão}

Este é um dos poucos estudos brasileiros que estimou o risco de internação de acidentados no trânsito. $\mathrm{O}$ risco médio encontrado de 19,4/100 vítimas é superior ao encontrado em estudo realizado em Belo Horizonte/Contagem-MG que foi de $16,0 \%{ }^{14}$ e em Londrina-PR, em que foi observado risco de $10,8 \%{ }^{15}$. Importante ressaltar que a internação da vítima é um indicador da gravidade do evento e significa parcela importante dos custos dos acidentes de trânsito.

Entre as categorias dos acidentados, os resultados mostraram riscos elevados para vítimas pedestres, ciclistas e motociclistas apontando a maior vulnerabilidade por exposição direta ao impacto com veículos

Tabela 3 - Distribuição das vítimas internadas, risco relativo e respectivo intervalo de confiança de 95\%, segundo características dos condutores. Maringá-PR, 2000.

Table 3 - Distribution of interned victims, their relative risk and their 95\% interval of confidence, according to the drivers' characteristics. Maringá-PR, 2000.

\begin{tabular}{|c|c|c|c|c|c|c|}
\hline Variável & $\begin{array}{l}\text { Número de } \\
\text { condutores }\end{array}$ & $\begin{array}{l}\text { №.e \% de } \\
\text { internação }\end{array}$ & $\begin{array}{c}\text { Risco de } \\
\text { internação (\%) }\end{array}$ & $\mathrm{RR}$ & IC (95\%) & $\mathrm{P}$ \\
\hline \multicolumn{6}{|l|}{ Residência } & 0,001 \\
\hline Residente & 2118 & $518(87,5)$ & 24,5 & 1,39 & $1,12-1,73$ & \\
\hline Não residente & 431 & $74(12,5)$ & 17,2 & 1 & - & \\
\hline \multicolumn{6}{|l|}{ Categoria } & 0,053 \\
\hline Ciclista & 103 & $25(4,2)$ & 24,3 & 1,05 & $0,74-1,50$ & \\
\hline Motociclista & 1069 & $235(39,2)$ & 22,0 & 0,95 & $0,82-1,11$ & \\
\hline Cond. de carro/caminhonete & 1258 & $290(48,4)$ & 23,1 & 1 & - & \\
\hline Cond. de veíc. transporte pesado/ônibus & 156 & $49(8,2)$ & 31,4 & 1,36 & $1,06-1,75$ & \\
\hline Cond. de demais veículos/outros & 8 & $-(0,0)$ & - & - & - & \\
\hline \multicolumn{6}{|l|}{ Número de cond. envolvidos no acidente } & 0,005 \\
\hline 1 & 865 & $231(38,6)$ & 26,7 & 1,24 & $1,08-1,44$ & \\
\hline 2 & 1650 & $354(59,1)$ & 21,5 & 1 & - & \\
\hline 3 ou mais & 80 & $14(2,3)$ & 17,5 & 0,82 & $0,50-1,32$ & \\
\hline
\end{tabular}


ou com objetos fixos e, portanto, sujeitas a traumas múltiplos de maior gravidade.

Estudos realizados na Eslovênia e em Belo Horizonte/Contagem-MG também mostraram associação da condição de pedestre com a gravidade das lesões e o óbito $^{14,16}$. O excesso do risco no atropelamento é atribuído à quantidade de energia liberada diretamente sobre o corpo das vítimas pelas duras superfícies dos veícu$\operatorname{los}^{14}$.

De modo geral, a cidade de Maringá oferece aos pedestres boas condições de circulação, pois reserva espaço amplo de calçadas com 3 metros de largura. No entanto, a largura ampla das ruas e avenidas, característica predominante de uma cidade planejada como Maringá, não permite travessia segura, especialmente fora das faixas de pedestres, existentes nos cruzamentos da cidade; e a imprudência dos condutores de veículos aumenta o risco de atropelamento ${ }^{17,18}$.

Quanto à vítima ciclista, que no presente estudo revelou risco significativamente maior de internação, estudos anteriores realizados em Maringá19-21 haviam apontado a importância da morbimortalidade por acidentes de trânsito envolvendo essa categoria. A bicicleta, além de constituir um veículo utilizado para lazer e esporte, apresenta-se como a alternativa mais econômica de transporte para determinados grupos sociais e categorias profissionais. Em Maringá, o uso deste veículo é bastante freqüente como meio de transporte, o que é facilitado pelas condições climáticas e topográficas da cidade.

Com relação aos motociclistas, categoria que no presente estudo apresentou risco maior de internação, nos últimos anos houve uma mudança do padrão de utilização de motocicletas, que passaram a ser usadas não somente como veículos de lazer, mas cada vez mais como instrumento de trabalho, especificamente em serviços de entregas rápidas ${ }^{22}$. Alguns trabalhos têm mostrado proporções importantes de motociclistas internados em relação ao total de vítimas de acidentes de trânsito, com comprometimento de pessoas jovens e do sexo masculino ${ }^{15,19,21,23}$. A cidade de Maringá apresenta a maior frota de motocicletas do Estado do Paraná, com 5,8 motocicletas para cada grupo de 100 habitantes, seguida de Londrina $(5,4)$ e Curitiba $(2,6)$.

O conflito entre diferentes usuários das vias públicas tende a prejudicar de forma mais grave os fisicamente mais vulneráveis $^{24}$. Neste sentido, a grande porcentagem das vítimas que foram internadas $(77,0 \%)$ é representada principalmente pelas categorias mais vulneráveis (pedestres, ciclistas e motociclistas).

$\mathrm{O}$ presente estudo mostra o risco de internação crescente com o aumento da idade das vítimas. A maior gravidade das lesões nos acidentados de mais idade tem sido relatada por outros pesquisadores $^{14,16,25}$.

Pesquisa realizada em Maringá, com vítimas idosas de acidente de trânsito mostrou que 52,0\% das vítimas encontravamse na condição de pedestre e, entre as que morreram, $87,5 \%$ eram pedestres ${ }^{21}$. O progressivo aumento do percentual de idosos na população brasileira e a adoção de estilo de vida que inclui cada vez mais um conjunto de atividades fora do domicílio tende a aumentar a exposição e o risco de atropelamentos. Atenção especial nos programas de redução da morbimortalidade por acidentes de trânsito precisa ser destinada a este segmento da população. Estudos realizados em outros países mostram a exposição de idosos principalmente como condutores de veículos, enquanto em nosso país, as vítimas fatais da terceira idade encontram-se, predominantemente, na condição de pedestre ${ }^{26}$.

A idade do condutor não representou neste estudo fator de risco para internação de acidentados, mas, alguns autores têm observado aumento dos riscos de internação e óbito de motoristas idosos ${ }^{27,28}$. Os autores apontam deficiências cognitivas, diminuição da agilidade psicomotora e redução da acuidade visual entre as deficiências cuja freqüência cresce com o avan- 
çar da idade. Essas deficiências atingem os condutores idosos e os idosos pedestres, ciclistas e motociclistas tornando-os mais vulneráveis a acidentes ${ }^{19}$.

Este estudo apontou que as vítimas que colidiram com veículo de transporte pesado ou ônibus apresentaram maior risco de internação. O porte desses veículos coloca em ampla desvantagem objetos ou pessoas que com eles colidem. O risco de internação cresce à medida que o outro veículo aumenta em massa ${ }^{15}$.

$\mathrm{O}$ achado de maior risco de internação das vítimas de acidentes ocorridos à noite ou de madrugada é compartilhado por outros autores que verificaram que os acidentes ocorridos no período noturno produziram lesões mais graves do que os ocorridos de dia ${ }^{16,27}$. Bastos et al. ${ }^{29}$ afirmam que os acidentes que ocorrem no período da noite apresentam maior gravidade em virtude de diversos fatores ligados ao meio ambiente (menor visibilidade) e aos usuários da via pública (excesso de velocidade, desrespeito aos semáforos, uso de álcool e drogas, entre outros). O reduzido volume de tráfego também propicia o desenvolvimento de altas velocidades, levando a acidentes de maior gravidade.

Quanto à variável região de ocorrência do acidente, observou-se que as vítimas acidentadas nas regiões Noroeste, Sudoeste e Centro, apresentaram riscos maiores de serem internadas, se comparadas às vítimas que sofreram acidente em outras regiões da cidade. Essas regiões possuem algumas características distintas e importantes, que poderiam auxiliar na compreensão da diferenciação dos riscos nesses espaços urbanos. A região Centro, que apresentou a maior freqüência de vítimas acidentadas $(31,2 \%)$, corresponde à área central da cidade e apresenta um fluxo importante de pedestres e veículos nas ruas, tendo em vista o predomínio das atividades comerciais e de prestação de serviço. Nessa região observa-se uma grande concentração de população residente, em função principalmente do crescimento vertical e centralizado ocorrido, sem cri- tério, nas décadas de 1980 e 1990. A região Sudoeste ocupa, entre todas as outras regiões, a maior área territorial, fazendo parte dela o parque industrial do município, shoppings atacadistas de confecção, além de uma grande área residencial. Quanto à região Noroeste, predominantemente residencial, grande parte teve um processo de ocupação mais recente e não planejado, tornando-se uma área carente de infra-estrutura urbana e conseqüentemente ocupada por uma população de menor poder aquisitivo. As regiões Sudoeste e Noroeste são separadas por uma rodovia estadual (PR 376), importante no sistema viário regional e estadual, e que apresenta grande fluxo de veículos de transporte pesado. Pela região Sudoeste passam ainda duas rodovias estaduais (PR 317/Foz do Iguaçu e PR 323/Mato Grosso de Sul) e o Contorno Sul, via rápida que desvia da região Centro, o tráfego pesado vindo de Londrina, Curitiba e São Paulo. Para entender melhor esse diferencial, seria necessária uma investigação com desenho apropriado, que permita conhecer com maior detalhamento os fatores que levam ao maior risco e que possibilite intervenções rápidas visando a redução desses eventos, uma vez que a heterogeneidade dos riscos de acidentes em diferentes espaços pode decorrer de fatores como o volume de tráfego, desenho e condição das vias de circulação, acesso diferenciado aos diversos modos de transporte, entre ou$\operatorname{tros}^{15}$.

$\mathrm{O}$ fato de condutores residentes envolverem-se em acidentes com maior risco de internação das vítimas, mesmo após ajuste para o horário do acidente e região da cidade em que ocorreu (Tabela 4), indicaria que a maior familiaridade do motorista com as vias e o trânsito da cidade poderiam levá-lo a imprimir maior velocidade ao veículo e aplicar menor atenção.

Os resultados deste estudo identificaram algumas variáveis de risco de internação que seriam indicadoras da vulnerabilidade das vítimas (ser pedestres, ciclista ou motociclista, ter 50 anos ou mais e 
Tabela 4 - Resultados da análise de regressão de Cox para o risco de internação. Maringá-PR, 2000.

Table 4 - Results of Cox regression analysis for the admittance risk. Maringá-PR, 2000.

\begin{tabular}{|c|c|c|c|}
\hline Variável & $\mathrm{RR}$ & IC (95\%) & $\mathrm{P}$ \\
\hline \multicolumn{4}{|l|}{ Categoria da vítima } \\
\hline Pedestre & 2,19 & $1,62-2,98$ & 0,0001 \\
\hline Ciclista & 1,65 & $1,23-2,22$ & 0,0010 \\
\hline Motociclista & 1,43 & $1,13-1,81$ & 0,0032 \\
\hline Ocupante de demais veículos e outros & 1,55 & $0,94-2,55$ & 0,0856 \\
\hline Ocupante de carro & 1 & - & - \\
\hline \multicolumn{4}{|l|}{ Faixa etária da vítima } \\
\hline$<20$ & 1 & - & - \\
\hline $20-29$ & 1,13 & $0,90-1,44$ & 0,3173 \\
\hline $30-49$ & 1,25 & $0,98-1,59$ & 0,0786 \\
\hline 50 e mais & 1,46 & $1,09-1,98$ & 0,0127 \\
\hline \multicolumn{4}{|l|}{ Colisão com trasporte pesado ou ônibus } \\
\hline Sim & 1,62 & $1,19-2,20$ & 0,0024 \\
\hline Não & 1 & - & \\
\hline \multicolumn{4}{|l|}{ Horário } \\
\hline Madrugada & 1,76 & $1,28-2,42$ & 0,0005 \\
\hline Manhã & 1,08 & $0,85-1,37$ & 0,5436 \\
\hline Tarde & 1,25 & $1,01-1,53$ & 0,0372 \\
\hline Noite & 1 & - & \\
\hline \multicolumn{4}{|l|}{ Região do município } \\
\hline Centro & 2,18 & $1,67-2,84$ & 0,0001 \\
\hline Sudeste & 1,16 & $0,82-1,64$ & 0,4032 \\
\hline Sudoeste & 2,37 & $1,74-3,22$ & 0,0001 \\
\hline Noroeste & 2,65 & $1,93-3,65$ & 0,0001 \\
\hline Rural & 1,15 & $0,28-4,70$ & 0,8462 \\
\hline Nordeste e Norte & 1 & - & - \\
\hline \multicolumn{4}{|l|}{ Residência do condutor } \\
\hline Residente em Maringá & 1,34 & $1,04-1,74$ & 0,0245 \\
\hline Não residente & 1 & - & - \\
\hline
\end{tabular}

colidir com veículo de transporte pesado ou ônibus), das condições do acidente (horário e região da cidade) e das características dos condutores (residência).

Quanto à idade das vítimas, é preciso considerar o processo de envelhecimento populacional em curso no país, e em Maringá, que revelou um aumento de $62,7 \%$ da população idosa do município, entre 1979 e $1998^{30}$. Visto que os riscos de internação aumentam com a idade, é preciso implementar ações voltadas à redução dos acidentes nesse grupo específico da população. O controle efetivo dos aci- dentes envolvendo vítimas idosas implica em transformação da concepção do espaço urbano que passe a contemplar o princípio da pluralidade, configurando cidades menos hostis às pessoas com mobilidade reduzida e/ou portadoras de alterações funcionais, como é o caso do idoso ${ }^{21}$. Embora se saiba que historicamente as ações voltadas para a redução dos acidentes de trânsito não têm considerado, de forma balanceada, as demandas dos diferentes tipos de usuários do sistema viário ${ }^{31}$, os resultados do presente trabalho, que mostram a vulnerabilidade dos diferentes ti- 
pos de vítimas, reforçam a importância de levar em consideração as necessidades e especificidades de todos os tipos de usuários do sistema viário no planejamento de ações que visem à redução dos acidentes.

Uma das limitações do presente estudo é o fato de utilizar dados secundários obtidos de diferentes fontes. Como foram incluídas as vítimas de acidentes atendidas pelo SIATE ou com registro de BO, é possível que vítimas de acidentes de nenhuma ou de pequena gravidade não tenham sido registradas, o que tenderia a aumentar o risco de internação estimado. Entretanto, o interesse do presente estudo foi incluir as vítimas com algum risco de internação e considerar os acidentes mais relevantes no que diz respeito aos prejuízos à saúde. Por outro lado, o SIATE atendeu 90,9\% das vítimas da coorte e houve registro de $\mathrm{BO}$ para $71,2 \%$ delas o que mostra a boa cobertura dos sistemas. Sendo procedentes de dados secundários, algumas variáveis apresentaram problemas de falta de registro (dados ignorados) e de qualidade da informação. $\mathrm{O}$ fato de não ter sido observada associação do estado de alcoolização da vítima com internação $(\mathrm{p}>=0,05)$, pode ter decorrido da falta de percepção do socorrista (na fonte SIATE) e/ou de autorização do condutor para a realização do teste de bafômetro ou dosagem alcoólica (na fonte BO). Assim como a falta de associação com o uso de equipamento de proteção e com as condições do local de ocorrência do acidente, poderiam decorrer da baixa freqüência desses registros nas fontes pesquisadas.

Embora não tenha sido objeto do estudo a análise dos custos das internações, estes certamente foram importantes, uma vez que o risco médio de internação encontrado foi superior ao referido por alguns autores, conforme visto anteriormente. Estudos revelam que as internações por AT contribuem de forma significativa para os custos médico-hospitalares, uma vez que a necessidade de internação hospitalar está diretamente relacionada à gravidade das lesões. Esses custos crescem de forma exponencial nos pacientes muito graves, que, embora sejam minorias em relação ao total das vítimas acidentadas, são os maiores responsáveis pelos altos custos do atendimento médico-hospitalar ${ }^{1,32}$.

Os resultados do estudo sinalizam que a busca de soluções para os problemas de trânsito requer um olhar interdisciplinar que contemple não só intervenções técnicas, mas também dimensões de ordem sociocultural $^{33}$ e de ações intersetoriais integradoras e efetivas.

\section{Referências}

1. Mello Jorge MHP, Koizumi MS. Gastos governamentais do SUS com internações hospitalares por causas externas. Rev Bras Epidemiol 2004; 7(2): 228-38.

2. Brasil, Ministério da Saúde. DATASUS, 2003. Disponível em <http:/ /www.datasus.gov.br>. Acessado em $10 \mathrm{de}$ abril 2006.

3. Híjar-Medina MC, Carrillo-Ordaz CE, Flores-Aldama ME, Anaya R, Lópes-Lópes MV. Factores de riesgo de lesión por accidentes de tráfico y el impacto de una intervención sobre la carretera. Rev Saude Publica 1999; 33(5): 504-12.

4. Brasil. Ministério da Saúde, Secretarias de Políticas de Saúde. Política Nacional de Redução da Morbimortalidade por Acidentes e Violência. Informes Técnicos Institucionais. Rev Saude Publica 2000; 34(4): 427-30.
5. Centers for Disease Control and Prevention (CDC). Achievements in public health, 1900-1999 motor-vehicle safety: a $20^{\text {th }}$ century public health achievement. MMWR Recommendations and Reports. Atlanta, 1999; 48(18):36974. Disponível em http://www.cdc.gov/epo/mmwr/ preview/mmwrtml/mm4818al.htm. Acessado 24 Julho 2000.

6. Marín-León L; Queiroz MS. Atualidade dos acidentes de trânsito na era da velocidade: uma visão geral. Cad Saude Publica 2000; 16(1): 7-21.

7. Departamento Nacional de Trânsito - DENATRAN. Política nacional de trânsito (PNT). Brasília, 1998. Disponível em <http:/ /www.mj.gov.br/denatran/ pnt.htm>. Acessado em 15 de agosto de 2000.

8. [FIBGE] Fundação IBGE. [informações on line]. Disponível em http://www.ibge.gov.br . Acessado em 1 de fevereiro de 2001. 
9. Prefeitura Municipal de Maringá. Secretaria de Planejamento. Perfil de Maringá, Divisão de Modernização Administrativa e Controle de Qualidade. Maringá; 1996.

10. Organização Mundial da Saúde, Volume 1: Classificação internacional de doenças e problemas relacionados à saúde. 10a rev. São Paulo: Centro Colaborador da OMS para a Classificação de Doenças em Português; 1993.

11. Teasdale G, Jennet B. Assessment of coma and impaired consciousness: a practical scale. Lancet 1974; 1(872): 81-4

12. Chanpion HR, Sacco WJ, Copes WS, et al. A revision of the Trauma Score. J Trauma 1989; 29: 623-9.

13. Hosmer DW, Lemeshow SL. Applied Logistic Regression. New York: John Wiley \& Sons; 1989.

14. Ladeira RM. Morbi-mortalidade por acidentes de trânsito em cinco hospitais de Belo Horizonte e Contagem, 1994/ 95 [dissertação de mestrado]. Belo Horizonte: Universidade Federal de Minas Gerais; 1995.

15. Andrade SM. Acidentes de transporte terrestre em Londrina-Paraná: análise das vítimas dos acidentes e das fontes de informação [tese de doutorado]. São Paulo: Faculdade de Saúde Pública, Universidade de São Paulo; 1998.

16. Simoncic M. Road accidents in Slovenia involving a pedestrian, cyclist or motorcyclist and a car. Accid Anal Prev 2001; 33: 147-56.

17. Carvalho Júnior BM, Cardoso JC, Soares VMVPP. Análise do banco de dados de trânsito da região urbana de Maringá com relação ao idoso no ano de 2003 [monografia de especialização]. Maringá: Universidade Estadual de Maringá; 2004.

18. Soares DFPP, Soares DA. Características das vítimas pedestres traumatizadas em acidente de trânsito em Maringá-PR. Cienc Cuid e Saúde 2002; 1(1): 61-5.

19. Soares DFPP. Vítimas de acidentes de trânsito ocorridos no perímetro urbano de Maringá-Paraná, em 1995 [dissertação de mestrado]. Londrina: Universidade Estadual de Londrina; 1997.

20. Scalassara MB, Souza RKT, Soares DFPP. Características da mortalidade por acidentes de trânsito em localidade da região Sul do Brasil. Rev Saude Publica 1998; 32: 12532.

21. Souza RKT, Soares DFPP, Mathias TAF, Andrade OG Santana RG. Idosos vítimas de acidentes de trânsito: aspectos epidemiológicos e impacto na sua vida cotidiana. Acta Sci Univ Estadual Mar. 2003; 25(1): 19-26.
22. Mello Jorge MHP, Gotilieb SLD, Laurenti R. A saúde no Brasil: análise do período de 1996 a 1999. Brasília: Organização Pan-Americana da Saúde; 2001.

23. Soares DFPP, Soares DA. Motociclistas vítimas de acidente de trânsito na Região Sul do Brasil. Acta Sci 2003; 25(1): 87-94.

24. Jolly BT. Commentary: bigger is better, but not for everyone. Ann Emerg Med. 1997; 30: 225-6.

25. Dessie T, Larson CL. The occurrence and driver characteristics associated with motor vehicle injuries in Addis Ababa, Ethiopia. J Trop Med Hyg 1991; 94: 395-400.

26. Minayo MCS. A violência sob a perspectiva da saúde pública. Cad Saúde Pública 1994; 10(S1): 7-18.

27. Zhang J, Lindsay J, Clarke K, Robbins G, Mao Y. Factors affecting severity od motor vehicle traffic crashes involving elderly drivers in Ontario. Accid Anal Prev 2000; 32: 117-25.

28. Morgan R, King D. O motorista idoso. JABRAMET 1996; 15(16): 4-8

29. Bastos YGL, Andrade SM, Soares, DA. Características dos acidentes de trânsito e das vítimas atendidas em serviço pré-hospitalar em cidade do Sul do Brasil, 1997/2000. Cad Saúde Publica. 2005; 21(3): 815-22.

30. Mathias TAF. A saúde do idoso em Maringá: análise do perfil de sua morbi-mortalidade [tese de doutorado]. São Paulo: Faculdade de Saúde Pública, Universidade de São Paulo; 2002.

31. Faria EO, Braga MGC. Proposta para minimizar os riscos de acidentes de trânsito em crianças e adolescentes. Cienc Saude Coletiva 1999; 4(1): 95-107.

32. Instituto de Pesquisa Econômica Aplicada. Impactos sociais e econômicos dos acidentes de trânsito nas aglomerações urbanas brasileiras. Pesquisa de custos médico-hospitalares/Ipea, ANTP. - Brasília: Ipea: ANTP; 2004.

33. Queiroz MS, Oliveira PCP. Acidentes de trânsito: uma visão qualitativa no Município de Campinas, São Paulo, Brasil. Cad Saude Publica 2002; 18(5): 1179-87.

Recebido em: 20/09/05

Versão reformulada reapresentada em: 10/04/06 Aprovado em: 12/05/06 